African Research Review

An International Multidisciplinary Journal, Ethiopia

Vol. 8(3), Serial No. 34, July, 2014:226-240

ISSN 1994-9057 (Print) ISSN 2070--0083 (Online)

DOI: http://dx.doi.org/10.4314/afrrev.v8i3.19

\title{
Effects of Reciprocal Peer Guidance on Adolescents' Attitudes to Family Responsibilities
}

\author{
Nwoye, Njide Chiamaka \\ Department of Guidance \& Counselling \\ Nnamdi Azikiwe University, Awka \\ Anambra State, Nigeria \\ E-mail: njnwoye@yahoo.com \\ Tel: +2348068480625
}

\begin{abstract}
This study sought to determine the effects of Reciprocal Peer Guidance (RPG) on students' attitudes to family responsibilities. The study was based on two research questions and two null hypotheses. The research design was quasi-experimental. Stratified random sampling and purposive sampling techniques were used to select 154 SS 11 students from Secondary Schools in Onitsha Urban of Anambra State. A set of questionnaire was used to collect data. The questionnaire was titled "Attitudes to family Responsibilities scale" (AFRS). The study, which lasted for nine weeks, utilized the RPG for the experimental group and CGC (Conventional Guidance and Counselling) for the control group. Data were analyzed using Mean scores to answer the research questions and analysis of Co-variance to test the null hypotheses. Findings indicated that Reciprocal Peer Guidance (RPG) was more effective for improving students' attitudes to family responsibilities than conventional Guidance and counselling (CGC). It was also found that the effect of RPG on the students' attitudes to family responsibilities did not significantly differ based on gender. The implications of these findings were that RPG could be effectively used in schools to improve attitudes to family responsibilities as it would enable peers to engage in social interactions as well as learn basic family skills from their peers. Based on
\end{abstract}


these findings, it was recommended that to enhance positive students' attitudes to family responsibilities, peer-based guidance strategies such as RPG should be adopted in addition to the conventional counselling currently being used in schools. The Counsellor-training programmes in institutions in Nigeria should include RPG in order to equip would-be guidance counsellors with the techniques involved in the strategy.

\section{Introduction}

In recent times in Nigeria, there has been increased attention to modifying adolescents' attitudes to family responsibilities. Family responsibilities are those family expectations, activities and obligations required from members of a family. Crouter and Head (2004) described family responsibilities as tasks, supports, roles, duties, conducts and relationship expected of a person as a member of the family. These family responsibilities are crucial for adolescent-parent relationships, family stability and moral development of the adolescent. Where adolescents have positive attitudes to their family responsibility, it could make them to develop respect for authorities, manifest desirable conducts in the home and outside and gain family skills for future living. Conversely, Alvarez (2005) pointed out that where students' attitude to family responsibility is negative, such attitudes could result in emotional turbulence for parents, lack of structure, moral decline and deviancy for the adolescent. Attitude therefore is a crucial issue in adolescent's family responsibility.

Attitude is described as a predisposition to behave or react in a certain way towards an object. Crelia and Tresser (1996), in Nwoye (2013) defined attitude as the beliefs and feelings that predispose reactions to objects, people and events. It refers to feelings and responses to issues. Erring her views on attitude, Nwoye (2013) affirmed that this indicates that attitude towards a particular object is a measure of the degree of affection or favourableness towards that object. Supporting this idea, Mmaduakonam (2008) asserted that attitude is an attribute that goes with character. The contextual definition adopted in this study is that adolescents' attitudes to family responsibilities are therefore the beliefs, dispositions, feelings and reaction of adolescents towards their family responsibilities.

Adolescent is an important development period, a transitional phase when important choices are being made, choices that sometimes affect the entire life as a grown up person. The adolescent period is the time of identity formation, liberation from families and life challenges (Erickson, 1968; Rinaldi, 2009). Although many adolescents adjust well to the challenges of transition, some experience difficult times of storm and stress. For others, it is a time of criminality, drugs and psychological problems which may have culminated from their negative attitude to family responsibilities. Akpobifre (2004) found that males show more manifestation of deviant behaviours in their families than females in areas such as careless handling of 
and vandalization of family property, keeping their homes untidy among others. These acts of irresponsibility affect the adolescents' overall attitude to life and may predispose them to manifest conduct problems in life.

The negative attitudes to family responsibilities bring pain to families, severe family relationship and erode the family values which are the basic foundation for societal well-being and development. It is therefore among the objectives of guidance and counselling in Secondary Schools to foster students' positive attitudes to family responsibilities.

A study conducted by the United-Nations Educational, Scientific and Cultural Organization (UNESCO, 2009) showed that in thirteen African countries including Nigeria, most techniques used by counsellors were inadequate to bring about desired attitudes to family responsibilities by students. In Secondary Schools, Conventional Guidance and Counselling are provided by professional guidance counsellors to a student or group of students. This is where a student or group of students are guided and counselled by a trained, knowledgeable and older person. This approach is used for the discussion and dissemination of information on general issues of concern and interest. The UNESCO (2009) stated further that the students lacked guidance and counselling for social issues in their families. Many school guidance counsellors work under adverse conditions such as poor status, too many students, high work load, among others. These conditions hinder them from adequately counselling students on family responsibilities. The result is that many students display negative attitudes to family responsibilities. In the same vein, Okeke (2011) reiterated that many adolescents have negative attitude to family responsibilities in Nigeria, noting that some adolescents disregard family authorities, ignore family traditions, among others. Where students have negative attitudes to their family responsibilities, it implies that conventional guidance and counselling is not enough. There is therefore the need for using additional guidance and counselling techniques for improving students' attitudes to family responsibilities. One of such techniques is Reciprocal Peer Guidance (RPG).

Reciprocal Peer Guidance (RPG) is an innovative guidance technique that is being increasingly emphasized in behaviour modification programmes. A peer is one that is of equal standing with another, one belonging to the same social group especially based on age, grade, or status. According to Carr (2009), RPG involves the guidance and counselling of Peers by others of their own age group and with similar experiences. This could be in a team, pair or one-to-one situation. The United Nations Children's Educational Fund (UNICEF, 2010) described reciprocal peer guidance as a process whereby those of the same societal group or social standing are trained to advise and guide each other. 
RPG consists of actions taken by individuals of the same age group that involve lending emotional and social assistance to each other in a reciprocal manner. Griffiths (2010) noted that reciprocal peer guidance is used to affect changes in knowledge, attitude, beliefs and behaviours of individuals or groups. A good example of such reciprocal peer guidance is evident in Igbo culture where the age grade system exists. This age grade system has been used to modify the behavior of members, fight social ills as well as contribute to community development. The reason being that peer interaction impacts significantly on the behaviour pattern of one another.

Hence, the researcher thinks that if peers are given opportunity to teach themselves, they will be able to impact knowledge on one another as well as guide one another to improve their attitudes than conventional counselling.

Peer guides are often selected from the group to be served, trained and given ongoing supervision to perform some key functions generally performed by professionals. Typically, peer guides are selected from the most capable members of the peer group, trained on how to listen and support one another but to offer little or no advice to other students being helped. Rather than being an advice giver or a problem solver the peer guide is a sensitive listener who uses communication skills to facilitate self-exploration and decision-making. The peers are also trained to encourage:

1. Genuineness - Rigorous honesty which shuns self deception

2. The essential freedom and autonomy of each individual to express him/herself through choice and

3. The awareness of family responsibility as an obligation not a burden.

After the training, they are assigned to groups to direct the RPG sessions by discussing problems, eliciting and summarizing information, critiquing the behavior of peers, giving and receiving feedback, correcting errors, questioning thought processes and justifications and explaining rationales for certain behaviour (Walker, Mclaren, Rummel and Koedinger, 2007). They also alternate roles with other peer members as guide and guided. These RPG activities differ from the conventional guidance technique (CGT) where the professional counsellor provides all guidance and counselling activities to students.

The researcher is motivated to study the effects of RPG on adolescents' attitudes to family responsibilities because of obvious reasons. In the Igbo society, age grade systems and youth association are being successfully used for peer guidance. Besides, during adolescence, peers become increasingly important for emotional well-being while the parents role decreases. The adolescents are more likely to share age related concerns with peers (Noller Feeney and Feeney, 2011). In company with peers, adolescents start to separate from their parents and to move into the adult world. Such 
separation might positively or adversely affect their attitudes to family responsibilities. Studies in Carr (2011); Noller, Feeney and Feeney (2011) have shown that confronted with personal, stressful or troubling issues, in most cases, the adolescents are more likely to share their fears and concerns with peers. In school situation, students are likely to contact fellow student when they are experiencing problems and concerns before they approach their teachers especially on family matters. Hence, de-Rosenroll (2010) noted that there is an increasing effort in several countries to employ a peer approach in their adolescent programmes and activities to facilitate the adolescents' improvement on their attitude to family responsibilities.

Reciprocal Peer Guidance could be used to improve situations by training capable peer helpers in the skills to deal with peer's interpersonal issues, under regular supervision, either by a qualified counsellor who would manage the RPG scheme. The researcher thinks that male and female students may perceive the strategy differently. This is buttressed by Strafford et al (2005), who opined that men and women may view their environment differently having found out that women are more likely than men to report that pollution and the global environment are of serious concern to them. In the same vein, Enrique et al (2005), while observing the role of gender in perceived environmental correlates explained that women may face a barrier in doing physical activity than men. Conversely, Konrad and Hartman (2001) found that gender was not a significant factor in attitudes to family responsibilities among people that participated in a peer education programme. The present study also focuses on the effect of RPG on the attitudes of students to family responsibilities and whether it impacts differently on male and female students. It therefore becomes important to empirically determine the effects of Reciprocal Peer Guidance on attitudes to family responsibilities among male and female adolescents, hence this study.

Many adolescents in Secondary School experience a mixture of cultures, namely, the traditional and the western type of cultures which are more often than not, conflicting in family responsibilities. The result is that many adolescents manifest negative attitudes to their family responsibilities. Nwokolo (2007) found that many adolescents appear to be disenchanted with their assigned family chores due to their negative attitudes to the family responsibilities which may lead to the erosion of the family responsibilities. In the same vein, Feinaver (2009) opined that where the family responsibilities are eroded, the societal structures and values may fall apart, deviant behaviours among adolescents may escalate and the very foundations of Societal development may crumble. Unfortunately, the Conventional guidance and counselling provided in schools are insufficient for improving adolescents' attitudes to family responsibilities. There is therefore a need to find ways of improving adolescents' attitudes to family responsibilities. 
Fortunately in Igbo society, age grade system (peers) and youth associations are being successfully used for peer guidance. In line with this, theorists, counsellors, psychologists such as Carr (2009), Egbochukwu (2007), Griffith (2010) and Tindall (2009) have proposed that Reciprocal Peer Guidance could be an effective guidance and counselling intervention for modifying adolescents' attitudes. Given this line of thought and the seemingly inadequacies of the conventional counselling method as shown in the increasing wave of adolescent negative attitudes to family responsibilities, a question that one may ask is "what is the effect of RPG on adolescents' attitudes to family responsibilities? Providing answers to this question, is the crux of this paper.

\section{Purpose of the study}

The main purpose of this study is to find out the effect which the use of Reciprocal Peer Guidance would have on the attitudes of adolescents to family responsibilities. Specifically, this study seeks to:

1. Find out the effects of Reciprocal Peer Guidance (RPG) on students' attitudes to family responsibilities when compared to Conventional Guidance and Counselling (CGC).

2. Determine if the effects of RPG on the attitudes of students to family responsibilities would differ due to gender.

\section{Research questions}

Two research questions guided the study.

1. What effects have Reciprocal Peer Guidance (RPG) on students' attitudes to family responsibilities when compared with Conventional Guidance and Counselling (CGC).

2. What effect does Reciprocal Peer Guidance (RPG) have on the attitudes of male and female students to family responsibilities?

\section{Hypotheses}

Two null hypotheses were tested in this study at 0.05 level of significance

Ho $_{1}$ There is no significant difference between the mean attitude to family responsibilities (AFR) ratings of students that received RPG and those who received CGC. 
$\mathbf{H o}_{2}$ The effects of RPG on students' attitudes to family responsibilities do not differ significantly due to gender.

\section{Methodology}

\section{Design of the study}

This study was based on a quasi-experimental design. This design was adopted because the traditional school settings, classroom grouping, rigid time-tabling and the location of the schools made it impossible for the researcher to randomly assign individual subjects to experimental and control groups. Harrington and Harrigan (2006) stated that the treatment design in this study by the researcher is the nonrandomized pre-test and post-test design. One of the groups was the experimental group that received Reciprocal Peer Guidance while the other was the control group that was exposed to conventional Guidance and Counselling. This research design allowed the researcher to assess how the intervention of RPG would impact adolescents' attitudes to family responsibilities by comparing the results of the control group with those who had received RPG.

\section{Area of the study}

This study was carried out in Onitsha Urban of Anambra State. It comprises two local government areas namely Onitsha North and Onitsha South LGA of Anambra State. Onitsha Urban is principally a commercial area, with many banks, large and small scale industries and government parastatals, inhabitants are mainly traders, public servants, artisans, vocational workers and civil servants. As a routine, most parents or guardians in the area leave their homes by 7.00am and return around 6pm. Many adolescent children in the area are either in school or in private business.

Thus, Onitsha Urban in Anambra State is appropriate for this study because adequate sample size is assured based on the large population of students and the availability of infrastructure for the Reciprocal Peer guidance services.

\section{Population of the study}

The population of this study consisted of the entire Senior Secondary II Students in the 22 State government owned Secondary Schools in Onitsha Urban of Anambra State. The population was 7,867 male and female students enrolled for the 2010/2011 academic sessions (Post Primary Schools Service Commission, PPSSC 2011)

\section{Sampling and sampling technique}

A sample of one hundred and fifty-four (154) students was selected for the study. Stratified random sampling and purposive sampling techniques were used to select the subjects for this study. The schools were stratified based on School type: boys and 
girls Schools. Two boys and two girls Schools were randomly selected using the sampling with replacement method. In each of the selected schools, one intact SS II class was selected. This yielded a total of 4 classes.

Two of the classes (one boys' and one girls') were used as the experimental group, while the other two classes (one boys' and one girls' school) were the control group. The experimental classes had 38 and 38 students (total 76) respectively. The control classes had 40 and 38 students (total 78) students. Hence the total sample size was 154 respondents.

\section{Instrument for data collection}

The instrument used to collect the required data was the "Attitude to Family Responsibilities Scale" (AFRS) designed by the researcher, to give the students the opportunity of identifying their attitudes to family Responsibilities. It was divided into two sections. The first section sought information on respondents' demographic variables namely gender, school and age. The second section had 34 statements on students' attitudes to family responsibilities. The items were on a four-point scale of strongly agree (4), agree (3), disagree (2), strongly disagree (1). These scores were aggregated for each item and the mean scores were obtained. The sum of each student score was taken to represent the student's level of attitude to family responsibilities. The scores of all students for each instrument were aggregated. The obtained total was divided by the number of students in the group to get the average mean. The mean values and gain scores were used to answer the research questions. The researcher was able to develop a wide range of attitude items on family responsibilities due to her wide exposure to literature, both empirical and theoretical in nature. The same instruments were used for Pre-test and Post-test. However, in the Post-test, items used in the Pre-test were rearranged in alphabetical order.

\section{Validation of the instruments}

The face and content validity of the research instrument were obtained through critical evaluation of the Attitudes to family Responsibilities scales by five lecturers, two from Measurement and Evaluation and three from the Guidance and Counselling Department of the faculty of Education, Nnamdi Azikiwe University, Awka. The validators reviewed the items in terms of content relevance and relatedness to the title for the study. Their suggestions were incorporated and ambiguities eliminated in the final copies of the instrument.

\section{Reliability of the instrument}

The reliability of the research instrument was determined by split half reliability method. Copies of the instrument were administered on a sample of 20 SS II students (10 males and 10 females) in a Co-educational School in Ogidi education zone. The responses to the instrument were separated into even and odd numbers. The sets of 
even and odd numbered scores for the instrument were correlated using the Pearson Product Moment Correlation. A reliability Co-efficient of 0.72 was obtained.

\section{Experimental procedure}

Prior to the beginning of this study, 4 schools were selected from the area of the study. From these schools, 154 SS II students in their intact classes were purposively selected and assigned to 2 groups. One group $(\mathrm{N}=76)$ participated in Reciprocal Peer Guidance (RPG) while the other group (N=78) received conventional Guidance \& Counselling (CG \& C). The study was designed to last for nine weeks using the normal school time table of 45 minutes for Guidance \& Counselling.

For the experimental group, (RPG), the first two weeks were used for training of the 18 peer guides nominated by the School Counsellors and who obtained the highest scores in the pretest given a week prior to the initiation of RPG and CGC interventions. The training was in 2 segments. The first segment lasted for one week (5 working days) and was for the training of the entire students in the experimental group. The segment involved five sessions of one hour each. The training which was carried out by the researcher and the school counsellors immediately after school, focused on the nature and scope of counselling, scope of peer counselling, basic helping and counselling skills, as well as roles and functions of these peer guides in their groups. It also included a session on adolescents' family responsibilities. After the training, the researcher identified the 16 best participating students and designated them as peer guides.

These peer guides were further given three days with six sessions of 45 minutes each training on reflections of peer guidance, adolescent counselling skills and facilitating peer interactions in counselling. After which the guides were assigned as peer team guides, while the remaining one guide was made a facilitator counsellor. Here, the students were introduced to the notion that they could guide and advise one another as friends and mates. Sample activities discussing family responsibilities were given to each student as a reference, and each RPG team took part in discussing family responsibilities. The control group consisted of conventional guidance and counselling techniques with the School Counsellors providing the services to the students - One-to-one and group counselling techniques involving questioning, reinforcement, listening and open communication on family responsibilities. A posttest on attitudes to family responsibilities were administered to both the experimental and control groups at the end of the nine weeks of treatment.

\section{Method of data analysis}

Mean score was used to answer the research questions and the analysis of Covariance (ANCOVA) at 0.05 level of significance was used to test the hypotheses. 


\section{Data presentation and results}

Research question1: What effects have Reciprocal Peer Guidance (RPG) on students' attitudes to family responsibilities when compared with conventional Guidance and Counselling (CGC)?

Table 1: Means for the effect of RPG and CGC on students' attitudes to family responsibilities.

\begin{tabular}{|l|l|l|l|l|}
\hline Variable & Pre-test & Post-test & Gain & Remark \\
\hline $\mathbf{N}$ & $\overline{\mathbf{X}}$ & $\overline{\mathbf{X}}$ & $\overline{\mathbf{X}}$ & \\
\cline { 1 - 1 } $\begin{array}{l}\text { Experimental 76 } \\
\text { Group (RPG) }\end{array}$ & 89.88 & 102.38 & 12.5 & RPG >CGC \\
\cline { 1 - 3 } $\begin{array}{l}\text { CONTROL GROUP } \\
\text { 78 (CGC) }\end{array}$ & 90.82 & 98.92 & 8.1 & \\
\hline
\end{tabular}

Table 1: Showed that the mean Pre-test score for 76 students in experimental group (RPG) was 89.88 which was less than the Mean score of 90.82 obtained by students in the control group. This indicates that prior to the commencement of the experiment; the mean attitude of students in the RPG group to family responsibilities was slightly less than those of their counterparts in the CGC group. However, the mean Post-test score of 102.38 obtained by students in experimental group (RPG) exceeded the mean Post-test score of 98.92 obtained by students in the control group. On the overall main treatment effects, the RPG group obtained a mean gain of 12.5 while the C.G.C group had a mean gain of 8.1. The mean gain of the students in the RPG group was higher than that of the CGC group. Hence, RPG has more positive effect on students' attitudes to family responsibilities than CGC.

Research question 2: What effects does Reciprocal Peer Guidance (RPG) have on the attitudes of male and female students to family responsibilities?

Table 2: Means for the effects of RPG on students' attitudes to family responsibilities.

\begin{tabular}{|l|c|c|c|c|l|}
\hline \multicolumn{7}{|l|}{ Variable } \\
\cline { 1 - 5 } Gender & $\mathbf{N}$ & $\overline{\mathbf{X}}$ & $\overline{\mathbf{X}}$ & $\overline{\mathbf{X}}$ & \multicolumn{1}{|c|}{ Remarks } \\
\hline Male & 38 & 86.13 & 102.58 & 16.45 & $\begin{array}{l}\text { RPG is effective for both male } \\
\text { and female student }\end{array}$ \\
\hline Female & 38 & 93.63 & 102.18 & 8.55 & \\
\hline
\end{tabular}


Table 2: Indicates that with respect to gender, male students in the RPG group had a mean gain of 16.45 while female students obtained a mean gain of 8.55 . Therefore, RPG had positive effects on the attitudes of male and female students to family responsibilities.

Hypothesis 1: There is no significant differences in the mean attitude to family responsibilities (AFRS) ratings of students that received $R P G$ and those who received $C G C$.

Table 3: The data in table 3 is the summary of ANCOVA for the main effects of RPG and CGC on students attitudes to family responsibilities which shows that Fcalculated for the treatment effects (4.727) exceeded the table value (3.84) at 1 and 149 degrees of freedom $(\mathrm{P} \geq 0.05)$. The decision is to reject the null hypothesis 1 . Thus, there was a significant difference in attitudes to family responsibilities between students that were exposed to RPG and those that received CGC.

Table 3: Summary of ANCOVA for the main effect of RPG and CGC on students' attitudes to family responsibilities

\begin{tabular}{|c|c|c|c|c|c|}
\hline $\begin{array}{l}\text { Source of } \\
\text { Variation }\end{array}$ & $\begin{array}{l}\text { Sum of } \\
\text { squares }\end{array}$ & $\begin{array}{l}\text { Degree } \\
\text { of } \\
\text { freedom }\end{array}$ & $\begin{array}{l}\text { Mean } \\
\text { square }\end{array}$ & $\begin{array}{l}\text { F- } \\
\text { cal }\end{array}$ & $F-$ crit $P \geq 0$ \\
\hline Corrected model & 670.090 & 2 & 335.045 & & \\
\hline Intercept & 13367.365 & 1 & 13367.365 & & \\
\hline Attitude test 1 & 215.031 & 1 & 215.031 & & \\
\hline Treatment model & 485.068 & 1 & 485.068 & 4.727 & $\begin{array}{l}3.840 \\
\text { significant }\end{array}$ \\
\hline Error & 15288.430 & 149 & 102.607 & & \\
\hline Total & 1555823.000 & 152 & & & \\
\hline
\end{tabular}

Corrected Total 15958.520151

Hypothesis 2: The effects of RPG on the status of student's attitudes to family responsibilities do not differ significantly due to gender.

Table 4: The ANCOVA 4 has $\mathrm{F}$ - calculated value of 0.92 and $\mathrm{F}$ - critical value of 3.97 at 1 and 73 degrees of freedom $(P \geq 0.05)$. The $F-$ calculated is less than $F-$ critical. Hence, the hypothesis of no significant difference is accepted. Hence, the 
effects of RPG on the status of students' attitudes to family responsibilities do not differ significantly due to gender.

Table 4: ANCOVA for the effects of RPG on the status of students' attitudes to family responsibilities by gender

\begin{tabular}{|l|l|l|l|l|l|l|}
\hline $\begin{array}{l}\text { Source of } \\
\text { Variation }\end{array}$ & $\begin{array}{l}\text { Sum of } \\
\text { squares }\end{array}$ & $\begin{array}{l}\text { Degree of } \\
\text { freedom }\end{array}$ & $\begin{array}{l}\text { Mean } \\
\text { square }\end{array}$ & F - cal & F - crit & P $\geq \mathbf{0 . 0 5}$ \\
\hline Corrected model & 9.421 & 2 & 4.710 & 0.71 & & \\
\hline Intercept & 10.568 .73 & 1 & 10.568 .73 & 160.049 & & \\
\hline Attitude test II & 6.460 & 1 & 6.460 & 0.98 & & \\
\hline Gender & 6.078 & 1 & 6.078 & 0.92 & 3.92 & $\begin{array}{l}\text { Not } \\
\text { Significant }\end{array}$ \\
\hline Error & 4820.513 & 73 & 66.034 & & & \\
\hline Total & 801461.00 & 76 & & & & \\
\hline
\end{tabular}

Corrected Total 4829.32475

\section{Discussion of the findings}

In table 1, the findings of the study indicated that students who participated in RPG and CGC had similar levels of negative attitudes to family responsibilities before the experiment began. However, after the experiment, the attitudes of students involved in RPG were significantly higher than that of those exposed to CGC. In other words, RPG was more effective in improving students' attitudes to family responsibilities than CGC. This finding agrees with Topping (2005) and Rinaldi (2009) whose studies showed that Peer Counselling is more effective in improving the attitudes of adolescents in Newzealand and Scotland than conventional guidance and counselling. Hence, the present finding is much in line with several other findings made for RPG interventions, because it increases students' focus on positive events in the environment, decrease attention to negative attitude and thereby encourage positive attitudes (Carr, 2009). The finding however disagreed with those of Poisson and Russel (1990) who found that Peer Counselling did not significantly improve Canadian students' attitudes more than conventional guidance.

The null hypothesis showed a significant difference in attitudes to family responsibilities of students that were exposed to RPG and those that received CGC. The result further showed that RPG actually influenced students' attitudes positively. This might be because of Peer Pairs, Self-disclosure and rewards for behaviour. In the RPG situation, students freely discussed their family responsibilities with their peers, such discussions could have helped to modify adolescents' attitudes to their family responsibilities.

In table 2, the findings showed that male students in RPG had a mean gain of 16.45 while the female students had a mean gain of 8.55. Therefore, RPG had positive effects on the attitudes of male and female students to family responsibilities. This is 
in line with Konrad and Hartman (2001) who found that gender was not a significant factor in attitudes to family responsibilities among people that participated in a Peer education programme. The null hypothesis revealed that there was no significant gender difference in the attitudes of the RPG students to family responsibilities. This may be because the researcher tried to avoid gender stereo typing during the experimental process. Also, having participated in RPG, both male and female students appeared to have developed enough attitudes to appreciate their family responsibilities.

\section{Conclusions}

This study reveals that Reciprocal Peer Guidance had a significant positive effect on students' attitudes to family responsibilities more than the conventional Guidance and Counselling. Specifically, RPG enhanced students' ability to achieve more scores in family responsibilities attitude tests more than CGC. In addition, gender was not a significant factor in the students' attitudes to family responsibilities under RPG. Based on this finding, it is concluded that the effective use of RPG can contribute significantly to increasing students' attitudes to family responsibilities irrespective of the students' gender.

\section{Recommendations}

Based on the findings discussed above, the following recommendations are made:-

i. To enhance students' attitudes to family responsibilities, new activity-based counselling strategies such as RPG should be adopted by Guidance counsellors in Secondary Schools.

ii. The teacher training Programmes in Nigeria should include Reciprocal Peer Guidance in order to equip would-be guidance counsellors with the techniques and processes involved in training students to use the strategy.

iii. The Anambra State Education Commission should provide on-the-job training to practicing guidance counsellors on the use of RPG through workshop, seminars, symposia and conferences.

iv. Guidance and Counselling specialists should collaborate with NERDC or other support services to produce RPG packages and materials on family responsibilities suitable for the Nigerian learners.

\section{References}

Alvarez; A. (2005) Attitudes and behaviours related to filial responsibility in Latino youth: variations by birth order, gender and immigration age. A Master of Arts thesis submitted in the college of Arts and Sciences, Liverpool University. 
Retrieved on $23^{\text {rd }}$ November 2009 from http://etd.gsu.edu/thesis/available/etd $1121200532149 /$ unrestricted/alvarezanabe 200512 Masti Pdf.

Akpobifre, O. (2004). Factors affecting potentials of Nigerian adolescents. Contemporary issues and research on adolescents 1 (1), $154-162$.

Carr, R. (2011). Theory and Practice of Peer Counselling. Educational and Vocational Guidance 42.1-10.

Carr, R. (2009). About Peer Coaching. Victoria, British Columbia: Peer Resources. Retrieved July 23, 2010 from http://www.peer.calcoach.html

Crelia, R. \& Tesser, A. (1996). Attitude heritability and attitude reinforcement: A replication. Personality and Individual Differences, In Nwoye N.C. (2013) Attitude of Mothers towards exclusive breastfeeding in Onitsha. Implications for family counselling. In Press.

Crouter, A.C. \& Head, M.R. (2004). Family Responsibilities and the Psychological adjustment of adolescent siblings and their parents. Journal of marriage and Family, 66, $147-162$.

De - Rosenroll, D.A. (2010). Peer helping. Time for a name change. Peer News 24 (1) 1 - 3. Retrieved on 24th January 2010 from http://www.peer.ca/peernews Jan 10. Pdf.

Egbochukwu, E. O. (2007). Effects of Reciprocal Peer Counselling in the enhancement of self-concepts of adolescents. Retrieved March 14, 2007, from http://www.scu.edu.au/schools/gcm/ar/arp/choice.htm/

Enrique Garcia Bengoechia. John C. Spence and Kerry R. Mc Gannon (2005) Gender Differences in perceived environmental correlates of physical activities. International of Behavioural Nutrition and Physical Activity. 2(12), 2 - 12.

Erikson, E.H. (1968). Identity, Youth and crisis. New York: Norton.

Feinaver, D. (2009). The relationship of implicit family process rules to adolescent Psychological Symptoms Marriage and Family Therapy 1, 7 - 16.

Griffiths, K (2010). Peer Coaching trains and chains Peer News 24 (1) 4 - 7. Retrieved on $24^{\text {th }}$ January 2010 from http://www.peer.ca/peernews Jan 10 . Pdf.

Harrington, T. F. \& Harringan, T. A. (2006). Practice and Research in Career Counselling and development - 2005. The Career Development Quarterly, 55, 98 - 167.

Konrad, A. \& Hartman, L. (2001). Gender difference in attitudes towards affirmative action programs in Australia: effects of beliefs, interests and attitudes towards women. Sex Roles 45/5/6:415 - 432.

Maduakonam, A. (2004). Parental awareness and Implementation of the rights of the child in Onitsha Urban. The counsellor 22, 222 - 236. In press 
Noller, S.T., Feeney, 1.0. \& Feeney, R - S. (2011). Using Peer Counselling to reduce acculturative stress among American refugees: Gender and racial differences, Adolescence, 31, 477 - 486.

Nwokolo, C. (2007). Family environmental variables and deviant behaviours among Secondary Secondary Students in Onitsha Education Zone. Nigerian Journal of Teacher Education and Teaching 3, (1) 171 - 179.

Nwoye, N.C (2013). Attitude of Mothers Towards Exclusive Breastfeeding in Onitsha. Implications for family counselling. In press

Okeke, V. (2011). Our Youths, our hope and their future. Nimo: Rex Charles and Patrick Limited.

Poisson, S. \& Russell, J. (1990). Assessment of involvement in a Peer Orientation Program. Canadian Journal of Counselling 24 (3) 191 - 199.

Rinaldi, D. (2009). Peer-helper intervention to reduce inappropriate school bus behaviour. Dissertation Abstracts International: Section B: the Sciences and Engineering $69,7-B, 4406$.

Stafford M, Cummins S. Macintyre S. Ellaway A \& Marmot M (2005). Gender Differences in the associations between health and neighbourhood environment Social Science and Medicine. 60(8). 1681 - 92.

Tindall, J.A (2009). Peer Power book one. Strategies for the professional leader, becoming an effective peer helper and conflict mediator. 4th Edition. New York: Routledge, Taylor \& Francis.

Topping, K. (2005). The Peer tutoring handbook: Promoting co-operative learning. Cambridge. Brookline Books.

UNESCO (2009). Peer approach in adolescent reproductive health education: Some lessons learned Bangkok, Thailand. Regional clearing House on Population Education and Communication Asia and pacific Regional Bureau for Education.

UNICEF (2010). Peer education: A guidance note. Retrieved on 12th: http://www.unicef.org/lifeskills/index 12078.htm

Walker, E., Mc Laren, B.M., Rummel, N., \& Koedinger, K.R. (2007). Who says three's a crowd? Using a cognitive tutor to support peer tutoring. In the proceedings of the 13th International Conference on Artificial Intelligence in Education (AIED 2007), $399-406$. 